\title{
SLC39A8 is a risk factor for schizophrenia in Uygur Chinese: a case-control study
}

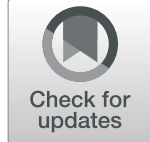

Xuemin Jian', Jianhua Chen ${ }^{1,3}$, Zhiqiang Li ${ }^{1,4}$, Zhijian Song ${ }^{1}$, Juan Zhou', Wei Xu', Yahui Liu', Jiawei Shen ${ }^{1}$, Yonggang Wang ${ }^{7^{*}}$, Qizhong $\mathrm{Yi}^{8^{*}}$ and Yongyong Shi $\mathrm{i}^{1,2,3,4,5,6,9,10^{*}}$

\begin{abstract}
Background: Schizophrenia is a severe mental disease with high morbidity and heritability. The SLC39A8 gene is located in $4 \mathrm{q} 24$ and encodes a protein that transports many metal ions. Multiple previous studies found that one of the most pleiotropic single nucleotide polymorphisms (SNPS) in SLC39A8, rs13107325, is associated with schizophrenia in the European population. However, the polymorphism of this locus is rare in other populations. In China, the Han Chinese and the Uygur Chinese are two ethnic populations that originate from different races.

Methods: A case-control study was conducted with 983 schizophrenia cases and 1230 healthy controls of the Chinese Uygur population. To validate the most promising SNP, meta-analyses were conducted with the Han Chinese and the European PGC2 data sets reported previously.

Results: $\mathrm{A}$ susceptible locus, $\mathrm{rs} 10014145$ ( $p_{\text {allele }}=0.014, p_{\text {allele }}=0.098$ after correction; $p_{\text {genotype }}=0.004, p_{\text {genotype }}=$ 0.032 after correction) was identified in case-control study of the Chinese Uygur population. Further, the association between rs10014145 and schizophrenia was supported by a meta-analysis of Han and Uygur Chinese samples (pooled OR $[95 \% \mathrm{Cl}]=1.10[1.03-1.17], Z=2.73, p=0.006$ ). The association between rs 10014145 and schizophrenia was not significant in a meta-analysis of combined Chinese and European samples (pooled OR $[95 \% \mathrm{Cl}]=1.07$ [1.00-1.14], $Z=1.88$, and $p=0.06$ ). In addition, the "CCAC" haplotype of rs4698844-rs233814-rs13114343-rs151394 was significantly associated with schizophrenia in Uygur Chinese ( $P=0.003$, corrected $p=0.012)$.
\end{abstract}

Conclusions: The results of this study support that SLC39A8 is a susceptible gene for schizophrenia in the populations of Han Chinese and Uygur Chinese in China, further studies are suggested to validate the association.

Keywords: SLC39A8, Schizophrenia, Case-control study, Meta-analysis, Uygur Chinese

\section{Background}

Schizophrenia is a severe chronic neuropsychiatric disease characterized by hallucinations, delusions and cognitive deficits with high morbidity and heritability [1]. The disease affects up to $1 \%$ of the world's population in a lifetime [2]. Although many pharmacological drugs are

\footnotetext{
*Correspondence: w100yg@163.com; 13079911689@126.com; shiyongyong@gmail.com

${ }^{7}$ Department of Neurology, School of Medicine, Renji Hospital, Shanghai Jiao Tong University, Shanghai 200127, People's Republic of China

${ }^{8}$ Psychological Medicine Center, The First Affiliated Hospital of Xinjiang Medical University, Urumqi, People's Republic of China

'Bio-X Institutes, Key Laboratory for the Genetics of Developmental and Neuropsychiatric Disorders (Ministry of Education) and the Collaborative Innovation Center for Brain Science, Shanghai Jiao Tong University, Shanghai 200030, People's Republic of China

Full list of author information is available at the end of the article
}

used to treat schizophrenia, their efficiency for many patients is poor [3].

The individual heritability of schizophrenia is $60-85 \%$ [2]. The etiology of schizophrenia remains far from being fully understood. Multiple genetic studies shed light on the importance of genetic factors. Psychiatric disorders are induced by both numerous genes each of them having a relatively small effect and environmental factors. To date, several susceptibility loci for schizophrenia have been identified by multiple genome-wide association studies (GWASs) [4-11]. The validation of these susceptibility variants of schizophrenia in different human populations remains important, which can provide for a meaningful understanding of its population genetic architecture and may provide more confident and precise targets before pathophysiological or new therapeutic experiments. 
The origins and genetic characteristics of different populations are generally different. In China, the Han Chinese population is the main ethnic group and the Chinese Uygur population is one of the minorities. The European population and the Uygur population have a Caucasian origin whereas that of the Han Chinese population is Mongolian. The Uygur Chinese primarily reside in Xinjiang Province, which is located on the northwest border of China, in the middle of Asia. This region experienced unceasing migrations and intermarriages during the Silk Road trade. Additionally, the Uygur population in the region has stable diet habits and lifestyle. These circumstances have all had an important influence on the typical genetic structure formed in the Chinese Uygur population $[12,13]$. The genetic structure in this region is proposed to be an admixture of the East and the West [14]. Therefore, the study of the genetic etiology of schizophrenia in this population is important.

Solute carrier family 39 member 8 (SLC39A8) belongs to the solute-carrier superfamily (SLC39). The SLC39 family plays an important role in maintaining metal ion homeostasis and is highly conserved across different species. SLC39A8 encodes a protein named ZIP8, which is responsible for the transport of the essential metals including ferrum $\left(\mathrm{Fe}^{2+}\right)$, manganese $\left(\mathrm{Mn}^{2+}\right)$ and zinc $\left(\mathrm{Zn}^{2+}\right)$, and the nonessential neurotoxic metal cadmium $\left(\mathrm{Cd}^{2+}\right)[15,16]$. In 2012, Carrera et al. first uncovered the association between rs13107325 in SLC39A8 and schizophrenia in a Galician population [17]. Rs13107325 is an exonic single nucleotide polymorphism (SNP) that alters the protein sequence from alanine (Ala; $\mathrm{C}$ allele) to threonine (Thr; T allele) at site 391. Thereafter, multiple studies validated the association between rs13107325 and schizophrenia. Based on whole-genome sequencing, rs13107325 is considered as the probably most functional missense mutation in 4q24 which is a region associated with schizophrenia [18]. In 2014, the Psychiatric Genomics Consortium (PGC) identified a new risk SNP around SLC39A8 for schizophrenia that has strong linkage disequilibrium with rs13107325 [19]. In addition, SLC39A8 is associated with many different traits such as blood pressure [20, 21], body mass index [22], Crohn's disease [23], serum levels of manganese [24] and HDL-cholesterol [25] and all the associations are linked to the rs13107325 variant. Thus, for the missense variant rs13107325, SLC39A8 is one of the most pleiotropic genes involved in many biological processes. However, the $\mathrm{T}$ allele of rs13107325 accounts for only $8 \%$ in European samples and this polymorphism is almost absent in Asians and Africans according to the 1000 Genome Project phase 3 [18]. Recently, Li et al. performed a GWAS and meta-analysis of Chinese samples (7699 schizophrenia cases and 18,327 controls, called the Bio-X sample) and the PGC2 samples (35,476 schizophrenia cases and 46,839 controls, called the PGC2 sample), and no SNPs in the SLC39A8 locus was found to be associated with schizophrenia genome-wide significantly $(p<5 \mathrm{E}-8)$ [11].

Although the significant association between SLC39A8 and schizophrenia in European Caucasian has been established, this study investigated whether the association between SLC39A8 and schizophrenia was also present in the Chinese Uygur population, which is considered to be genetically admixed [14]. A case-control association study was conducted to investigate the relationships between seven SNPs in SLC39A8 and schizophrenia in 983 unrelated schizophrenia cases and 1230 healthy controls of the Chinese Uygur population. To validate the most promising SNP, meta-analyses was conducted with Han Chinese and PGC2 datasets reported previously.

\section{Materials and methods Samples/subjects}

A total of 983 unrelated schizophrenia cases (611 males and 372 females) and 1230 healthy controls (635 males and 595 females) were recruited in this study. The mean age \pm SD of schizophrenia cases and healthy controls were $40.59 \pm 12.35$ years and $43.03 \pm 13.12$ years, respectively. All samples including cases and controls were recruited from the Chinese Uygur population living in Xinjiang Province, China. Most patients were outpatients, but some were stable in-patients. All patients were interviewed by at least two independent psychiatrists strictly according to Diagnostic and Statistical Manual of Mental Disorders Fourth Edition (DSM-IV) based on the Structured Clinical Interview for DSM-IV Axis I Disorders (SCID-I) [26]. The healthy controls were recruited by means of advertisement and announcements on bulletin boards from the general Uygur population. Before collecting blood samples, the healthy controls were screened by psychiatrists. Healthy controls with a family history of psychiatric disorders or with a severe medical illness were excluded. The purpose and potential risks of the study were fully described to the participants and the participants signed informed consents before data collection. The study proposal and procedures were reviewed and approved by the local Ethical Committee of Human Genetics. This study was conducted in accordance with The Code of Ethics of the World Medical Association (Declaration of Helsinki).

\section{SNP selection, DNA extraction and genotyping}

SLC39A8 gene is located in chromosome $4 \mathrm{q} 24$ and has a full length of 83,528 bp DNA. SLC39A8 contains 8 exons and 7 introns in total.

The common SNPs of SLC39A8 was selected from the HapMap (http:// hapmap.ncbi.nlm.nih.gov/) of the Han Chinese population in Beijing, China. Subsequently, a total of seven tag SNPs including rs233814, rs233820, rs10014145, rs4698844, rs151394, rs985989, and rs13114343 


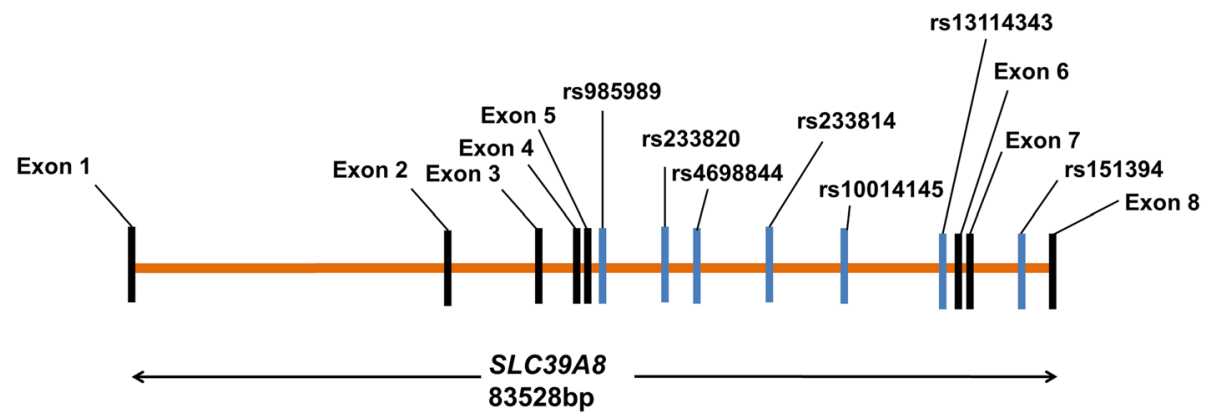

Fig. 1 Positions of seven single nucleotide polymorphism in the SLC39A8 gene

across the SLC39A8 gene were selected by Haploview software version 4.2. The linkage disequilibrium $r^{2}$ threshold was set as 0.8 and the minor allele frequency was greater than 0.05. All seven SNPs of SLC39A8 are intron variants. The relative location of these 7 SNPs in SLC39A8 were designated by Vector NTI (www.invitrogen.com/VectorNTI) and are shown in Fig. 1. Table 1 also provides the information of these seven SNPs.

The genomic DNA of the subjects was extracted from peripheral blood samples using a Quick Gene DNA whole blood kit L (FUJIFILM) according to the manufacturer's protocol. The SNPs in this study were genotyped by the Sequenom MassARRAY matrix-assisted laser desorption ionization-time of flight (MALDI-TOF-MS) mass spectrometry platform (Sequenom Inc., San Diego, CA, USA).

\section{Statistical analyses}

For the single site association study, the allele and genotype frequency calculations, the pair-wise linkage disequilibrium analysis were all conducted by the SHEsisPlus online software platform (http://shesisplus.bio-x.cn/ SHEsis.html) [27, 28]. All of the $p$ values presented are two-sided and only $p<0.05$ were considered as significant. The $p$-values were adjusted using the Bonferroni correction method. The Bonferroni correction states that if an experimenter is testing $\mathrm{n}$ independent hypotheses on a set of data, then the statistical significance level that should be used for each hypothesis separately is $1 / n$-fold times what it would be if only one hypothesis was tested.
Statistical power was post hoc calculated using the G*Power 3.1.9.4 [29].

\section{Meta-analysis}

Association statistics from the Han Chinese Bio-X and European PGC2 datasets were extracted for the most significant SNP in the Chinese Uygur population analysis [11]. The meta-analysis was performed using RevMan5.3. Cochran's Q test and $I^{2}$ were used to detect the heterogeneity of the odds ratios. If $P>0.05$ and $I^{2}<50 \%$, no significant heterogeneity occurred among the analyses and the fixed effects model (Mantel-Haenszel) was used to pool the ORs; and if $p<0.05$ or $I^{2}>50 \%$, random effects model was selected [30].

\section{Results}

The average call rate of all SNPs was 0.988 (Table 1). In the healthy control group, no deviation from HardyWeinberg equilibrium was found at the significance threshold being $p<0.05$ (Additional file 1: Table S1).

\section{Single SNP association analysis}

The allele and genotype of seven polymorphic SNPs in SLC39A8 for both schizophrenia and normal control groups of Uyghur Chinese were statistically analyzed as shown in Table 2. Rs233814, rs10014145, rs4698844, rs151394, rs985989, and rs13114343 had two alleles and rs233820 had three alleles. As shown in Table 2, rs10014145 $\quad\left(p_{\text {allele }}=0.014, \quad \mathrm{Chi}^{2}=5.999, \quad\right.$ OR $\quad[95 \%$

Table 1 Information of the single nucleotide polymorphisms (SNPS) in SLC39A8

\begin{tabular}{|c|c|c|c|c|}
\hline SNP ID & Chromosome & Function & Polymorphism & Call rate $^{a}$ \\
\hline rs233814 & $102,287,546$ & Intron variant & $\mathrm{C} / \mathrm{T}$ & 0.996 \\
\hline rs233820 & $102,301,031$ & Intron variant, UTR variant 3 prime & $C / G / A$ & 0.994 \\
\hline rs10014145 & $102,279,420$ & Intron variant & $A / G$ & 0.97 \\
\hline rs4698844 & $102,296,823$ & Intron variant & $\mathrm{C} / \mathrm{T}$ & 0.995 \\
\hline rs151394 & $102,263,495$ & Intron variant & $C / G$ & 0.987 \\
\hline rs985989 & $102,304,098$ & Intron variant & $\mathrm{G} / \mathrm{T}$ & 0.984 \\
\hline rs13114343 & $102,268,259$ & Intron variant & $\mathrm{A} / \mathrm{G}$ & 0.99 \\
\hline
\end{tabular}

${ }^{a}$ Each call rate was calculated in combined cases and controls 


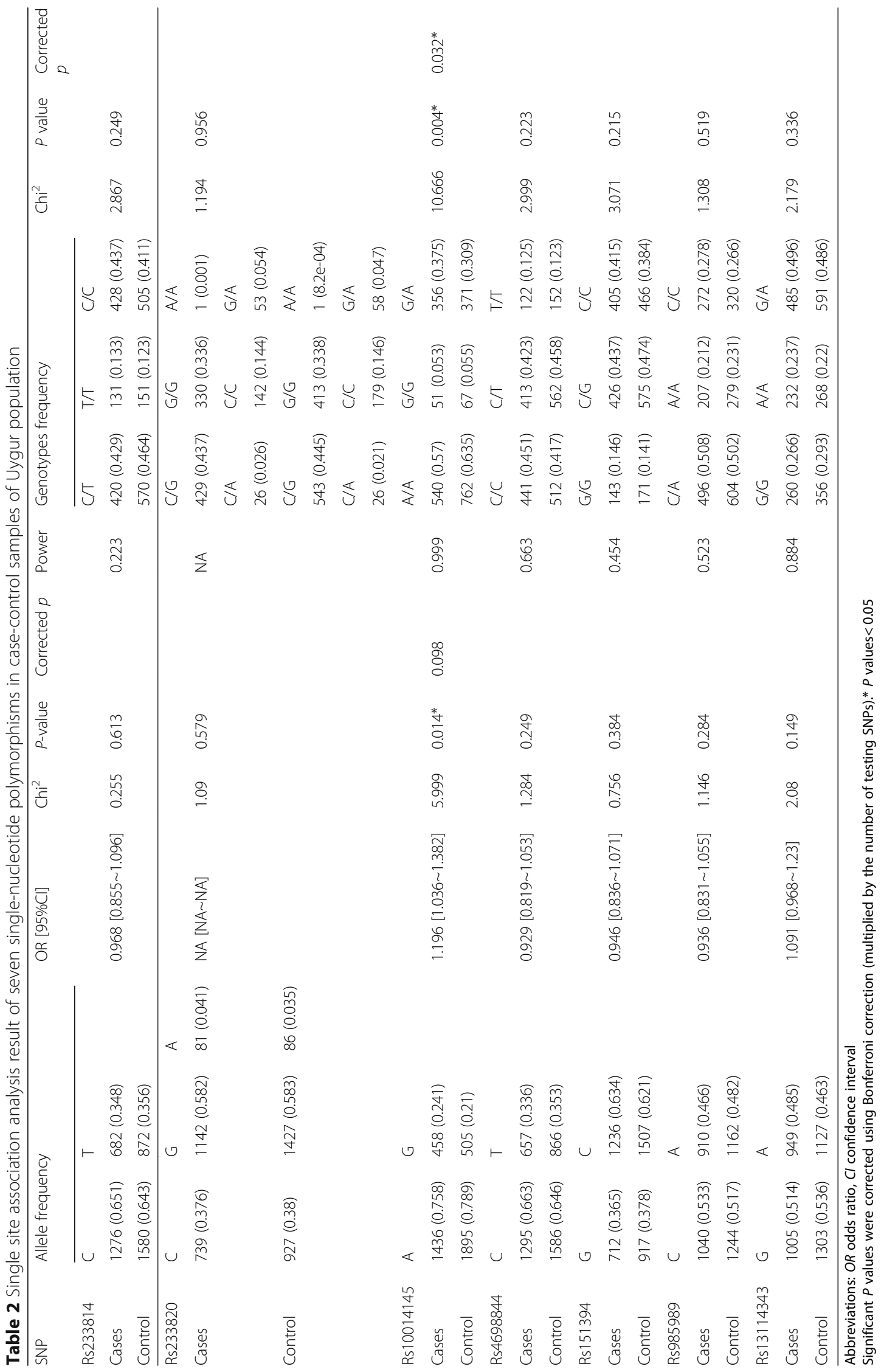




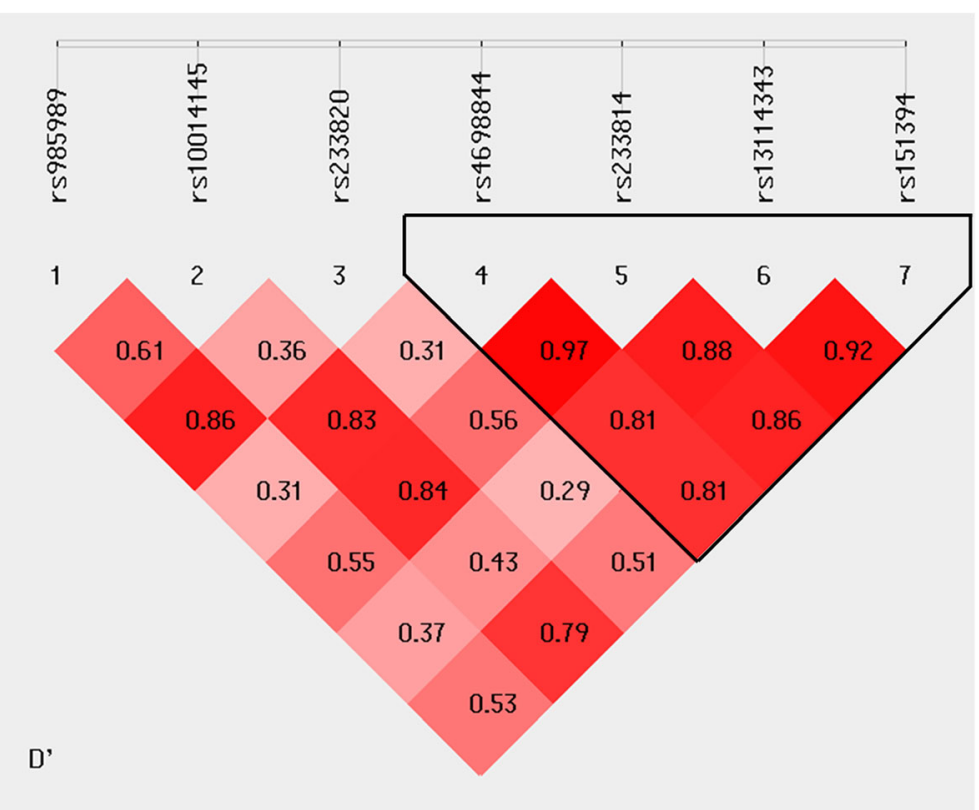

Fig. 2 Linkage disequilibrium analysis of seven SNPs in the schizophrenia samples of the Uygur population

confident interval $(\mathrm{CI})]=1.196[1.036 \sim 1.382] ; p_{\text {genotype }}=$ $\left.0.004, \mathrm{Chi}^{2}=10.666\right)$, showed both allele and genotype were significantly associated with schizophrenia. However, the allele association between rs10014145 and schizophrenia was eliminated after Bonferroni correction $\left(p_{\text {allele }}=0.014, p_{\text {allele }}=0.098\right.$ after correction; $p_{\text {geno- }}$ type $=0.004, p_{\text {genotype }}=0.032$ after correction $)$.

\section{Haplotype analysis}

The pairwise linkage disequilibrium D' values among the seven SNPs were calculated in different sample sets. The SNPs with D'>0.75 in separated sample sets were classified as in the same block and rs4698844rs233814-rs13114343-rs151394 was identified as one haplotype block as shown in Fig. 2. In this block, one haplotype "CCAC" showed significant association with schizophrenia (corrected $p=0.012$, OR $[95 \% \mathrm{CI}]=$ 1.296 [1.09 1.54]) (Table 3).

\section{Further validation of rs10014145}

Meta-analyses of the association between rs10014145 and schizophrenia were conducted. First, a meta-analysis was performed for the Uygur Chinese samples and the Han Chinese (Bio-X) samples. Because no heterogeneity was detected in the combined two independent samples $\left(I^{2}=42 \%\right.$, $\mathrm{Chi}^{2}=1.74, p=0.19$ ), the fixed effects model was used to test the significance of rs10014145 in these samples. A significant association was detected between rs10014145 and schizophrenia in the combined Chinese Uygur and Han Chinese populations (pooled OR [95\% CI] $=1.10$ [1.03-1.17] $\mathrm{Z}=2.73$, and $P=0.006$ ) as shown in forest plot of Fig. 3. Furthermore, a meta-analysis was conducted including the Chinese multiple ethnic samples and the Psychiatry Genomics Consortium (PGC2) of European samples. The random effects model was chosen for further analysis because heterogeneity was detected in the three samples $\left(I^{2}=62 \%\right.$, $\left.\mathrm{Chi}^{2}=5.23, p=0.07\right)$. The forest plot of this meta-analysis of the association between rs10014145 and schizophrenia in

Table 3 Haplotype analysis of SLC39A8 in case-control samples of Uygur population

\begin{tabular}{llllllr}
\hline Haplotype & Case (freq) & Control (freq) & OR [95\% Cl] & Chi $^{2}$ & $p$ & Corrected $P$ \\
\hline rs4698844-rs233814-rs13114343-rs151394 & & & & \\
CTGG & $622(0.316)$ & $795(0.323)$ & $0.969[0.853 \sim 1.1]$ & 0.231 & 0.63 & 0.177 \\
CCAC & $298(0.151)$ & $298(0.121)$ & $1.296[1.09 \sim 1.54]$ & 8.688 & $0.003^{*}$ & $0.012^{*}$ \\
CCGC & $271(0.137)$ & $349(0.141)$ & $0.967[0.815 \sim 1.147]$ & 0.147 & 0.701 & 0.98 \\
TCAC & $595(0.302)$ & $767(0.311)$ & $0.957[0.842 \sim 1.089]$ & 0.428 & 0.512 & 0.195 \\
\hline
\end{tabular}




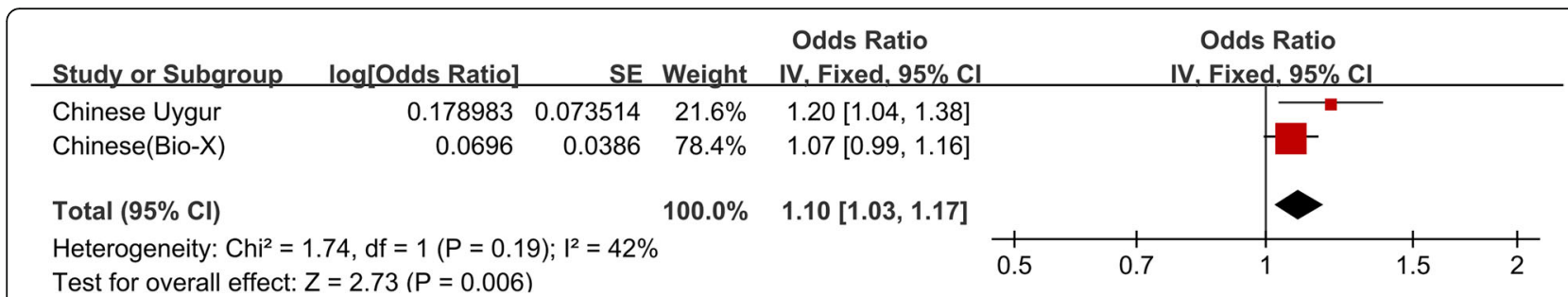

Fig. 3 Forest plot of association between rs10014145 and schizophrenia in Chinese samples including Uygur and Han Chinese. OR, odds ratio; Cl, confidence interval. Area of the square represents the weight of each statistical sample; horizontal lines represent OR and 95\% Cl of rs 10014145 in two independent samples. The black diamond represents the total $95 \% \mathrm{Cl}$ of rs 10014145 estimated in meta-analysis

the Chinese population and European samples is shown in Fig. 4. The association between rs10014145 and schizophrenia was not validated in three samples (pooled OR [95\% CI] $=1.07[1.00-1.14], \mathrm{Z}=1.88, p=0.06)$.

\section{Discussion}

The association between SLC39A8 and schizophrenia in European populations was discovered in multiple studies, and all researches then focused on the most pleiotropic variant, rs13107325. However, rs13107325 is monomorphic and the $\mathrm{T}$-allele with schizophrenia risk is completely nonexistent in African and Asian populations according to the 1000-Human-Genome project. The explanation of why this polymorphism disappeared in these populations is ascribed to recent positive selection [31-34]. For this report, a case-control study was conducted in the Chinese Uygur population and rs10014145 in $S L C 39 A 8$ was identified as significantly associated with schizophrenia in both allele and genotype distributions; however, after correction for multiple testing, the association was only significant for genotype distributions $\left(p_{\text {allele }}=0.014, p_{\text {allele }}=0.098\right.$ after correction; $p_{\text {geno- }}$ type $=0.004, \quad p_{\text {genotype }}=0.032$ after correction). This association was further validated by the meta-analysis of the multiple Chinese ethnic groups $(P=0.006)$. Although this association was not validated by the meta-analysis of the Chinese population with the European population, the statistical $p$-value was close to $0.05(p=0.06)$. In conclusion, a new risk locus in Chinese Uygur population was identified in this study, providing new evidence of the association between $S L C 39 A 8$ and schizophrenia.

SLC39A8 encodes a transmembrane protein named ZIP8. ZIP8 transports numerous metal ions such as ferrum, manganese, and zinc from the extracellular environment or intracellular compartments to the cytosol. These metal ions are necessary for many physiological processes in the brain; however, in excess, these ions may cause neurotoxicity [35-37]. For example, the over $20 \%$ of zinc distributed in synaptic vesicles of glutamatergic neurons demonstrates the functional relevance of this metal in neurotransmission [38, 39]. In addition, many of these ions can be cofactors of the multiple enzymes that function in the nervous system, such as monoamine oxidase (dopamine), tryptophan hydroxylase (serotonin), tyrosine hydroxylase (catecholamines), glutamine synthetase and superoxide dismutase. Of note, SLC39A8 can also transport the non-essential, toxic metal cation, cadmium [40]. Cadmium can mimic calcium which plays an important role in neurotransmission; and the exposure to acute doses of cadmium cause immediate damage in the central nervous system and other organs [41]. Zhang, et al. found that the ZIP8 Ala391-to-Thr391 substitution had an effect on intracellular cadmium accumulation and they suggested that pleiotropic effects of rs13107325, which is involved in multiple biological characters including schizophrenia, may attribute to cadmium-induced cell toxicity, highlighting the prominent effect of cadmium transmission [42].

\begin{tabular}{|c|c|c|c|c|c|c|c|c|}
\hline Study or Subgroup & log[Odds Ratio] & SE & Weight & \multirow{2}{*}{$\begin{array}{l}\begin{array}{c}\text { Odds Ratio } \\
\text { IV. Random, } 95 \% \mathrm{Cl}\end{array} \\
1.20[1.04,1.38]\end{array}$} & \multicolumn{3}{|c|}{$\begin{array}{l}\text { Odds Ratio } \\
\text { IV. Random, } 95 \% \mathrm{Cl}\end{array}$} & \\
\hline Chinese Uygur & 0.178983 & 0.073514 & $15.3 \%$ & & & & $\longrightarrow$ & \\
\hline Chinese(Bio-X) & 0.0696 & 0.0386 & $32.3 \%$ & $1.07[0.99,1.16]$ & & & & \\
\hline European(PGC2) & 0.025903 & 0.0114 & $52.4 \%$ & $1.03[1.00,1.05]$ & & & & \\
\hline \multicolumn{3}{|c|}{ Total $(95 \% \mathrm{Cl})$} & $100.0 \%$ & $1.07[1.00,1.14]$ & & & & \\
\hline \multicolumn{5}{|c|}{$\begin{array}{l}\text { Heterogeneity: } \mathrm{Tau}^{2}=0.00 ; \mathrm{Chi}^{2}=5.23, \mathrm{df}=2(P=0.07) ; I^{2}=62 \% \\
\text { Test for overall effect: } Z=1.88(P=0.06)\end{array}$} & 0.7 & 0.85 & 1.2 & $1+5$ \\
\hline \multicolumn{9}{|c|}{$\begin{array}{l}\text { Fig. } 4 \text { Forest plot of the association between rs10014145 and schizophrenia in Chinese and European populations OR, odds ratio; } \mathrm{Cl} \text {, } \\
\text { confidence interval }\end{array}$} \\
\hline
\end{tabular}


This study identified a new risk locus for schizophrenia, rs10014145. Although rs10014145 is an intronic SNP of SLC39A8, it has been reported that rs10014145 is correlated with cadmium concentrations in human blood and urine. Women who carry AG or GG of rs10014145 have a higher concentration of erythrocyte cadmium than those with the AA genotype [43]. In this study, the frequency of genotype GA was significantly higher in patients with schizophrenia than that in normal controls, whereas the frequency of genotype AA was relatively higher in the normal counterparts. The SZDB eQTL data show an association between rs10014145 and three solute-carrier family genes, SLC16A2, SLC25A23, and SLC5A10 ( $p=0.040,0.013$ and 0.036 respectively). However, no correlation was detected between rs10014145 and SLC39A8 [44]. Moreover, rs10014145 is predicted to have regulatory potential according to the RegulomeDB analysis [45]. On the basis of the collected results, we propose that the association of $S L C 39 A 8$ with schizophrenia partly depends on its function in the transport of metal ions, particularly cadmium transportation and in the maintenance of brain homeostasis.

In addition, gene expression pattern and epigenetic regulation provide additional evidence that $S L C 39 A 8$ is relevant to schizophrenia. SLC39A8 is widely expressed in many tissues, including the brain and is one of the most significantly upregulated genes in schizophrenia [46]. Furthermore, in the comparison of the post-mortem human brain tissue of schizophrenia patients and healthy controls, SLC39A8 is one of the most differentially methylated genes in CpG islands of the promoter region, as determined by genome-wide DNA methylation analysis [47]. The aberrant expression pattern of SLC39A8 may indicate that the gene is involved in the genesis of schizophrenia.

SLC39A8 is one of 14 members affiliated with the SLC39 family that are responsible for the transport of metal ions. Other family members in the SLC39 family are also identified as relevant to psychiatric disorders. For example, $S L C 39 A 3$ is associated with bipolar disorder according to GWAS analyses [48, 49]. SLC39A11 was revealed as one of the most significant genes in a GWAS of major depressive disorder although it did not reach genome wide significance [50].

\section{Conclusions}

In conclusion, this study provides new evidence of the association between $S L C 39 A 8$ and schizophrenia. The relevance of rs13107325 to schizophrenia is widely described; however, this susceptibility locus in the European population is almost monomorphic in other populations. In this study, a case-control study was performed and a new risk genetic locus for schizophrenia, rs10014145, was found in SLC39A8 in the Chinese Uygur Ethnic population. The association between rs10014145 and schizophrenia was further confirmed through meta-analysis. The primary limitation of this study was the limited sample size. In addition, the genetic structure of schizophrenia in Chinese Uygur population requires further exploration. Although the risk locus of SLC39A8 for schizophrenia in the Chinese population was validated, further functional studies are necessary to support this association.

\section{Additional file}

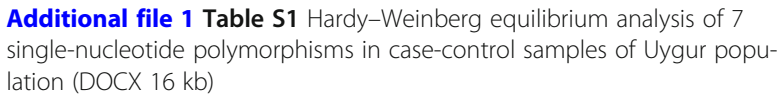

\section{Abbreviations}

DSM: Diagnostic Criteria of American Diagnostic and Statistical Manual of Mental Disorders; GWAS: Genome-wide association study; LD: Linkage disequilibrium; OR: Odds Ratio; PGC: Psychiatric Genomics Consortium; SLC39A8: solute carrier family 39 member 8; SNP: Single-nucleotide polymorphism; UTR: Untranslated region

\section{Acknowledgements}

We would like to acknowledge the all participants in the study.

\section{Authors' contributions}

YYS, YGW, QZY were the overall principal investigators for the study who conceived the study and obtained financial support, and they were responsible for study design and supervised the entire study. XMJ, JHC, ZQL participated in the study design. QZY and JHC supervised the diagnosis of patients and subject recruitment. XMJ, ZQL, ZJS and JWS performed statistical analyses. XMJ, JHC, JZ, WX and YHL performed the experiments. YYS supervised the experiments and data analyses. The manuscript was drafted by XMJ under the supervision of YYS, who synthesized the manuscript. All authors critically reviewed the article and approved the final manuscript

\section{Funding}

This study was supported by the 973 Program (2015CB559100), the 863 project (2012AA02A515), the Natural Science Foundation of China (U1804284,31325014, 81130022, 81272302, 81421061, 31770800, 81571329), the National High Technology Research and Development Program of China (2012AA021802), the Program of Shanghai Academic Research Leader (15XD1502200), National Program for Support of Top-Notch Young Professionals, Shanghai Key Laboratory of Psychotic Disorders (13dz2260500), "Shu Guang" project supported by Shanghai Municipal Education Commission and Shanghai Education Development Foundation (12SG17), the Shanghai Municipal Education Commission-Gaofeng Clinical Medicine Grant Support (20161414), the National Key R\&D Program of China (2016YFC0903402), Shanghai Science and Technology Committee (17JC1402900, 17490712200) and Project of Shanghai Health and Family Planning Commission, Shanghai municipal health commission (201540114, ZK2015B01). The funding bodies were not involved in the design of the study in collection, analysis, or interpretation of data or in writing the manuscript.

\section{Availability of data and materials}

All data generated or analysed during this study are included in this published article.

\section{Ethics approval and consent to participate}

The study proposal and procedure were reviewed and approved by local Ethical Committee of Human Genetics. Informed consents were signed by the participants prior to data collection. Our study is instructed by Ethics Committee of First Affiliated Hospital of Xinjiang Medical University (20160218-23) and Ethics Committee of Shanghai Jiao Tong University (M16042). 


\section{Consent for publication}

Not applicable.

\section{Competing interests}

The authors declare no competing financial interests.

\section{Author details}

'Bio-X Institutes, Key Laboratory for the Genetics of Developmental and Neuropsychiatric Disorders (Ministry of Education) and the Collaborative Innovation Center for Brain Science, Shanghai Jiao Tong University, Shanghai 200030, People's Republic of China. ${ }^{2}$ Shanghai key laboratory of Sleep Disordered Breathing, Shanghai Sixth People's Hospital, Shanghai Jiao Tong University, Shanghai, People's Republic of China. ${ }^{3}$ Shanghai Key Laboratory of Psychotic Disorders, Shanghai Mental Health Center, Shanghai Jiao Tong University School of Medicine, Shanghai 200030, People's Republic of China. ${ }^{4}$ Affiliated Hospital of Qingdao University and Biomedical Sciences Institute of Qingdao University (Qingdao Branch of SJTU Bio-X Institutes), Qingdao University, Qingdao, Shandong 266003, People's Republic of China. Institute of Social Cognitive and Behavioral Sciences, Shanghai Jiao Tong University, Shanghai 200030, People's Republic of China. Institute of Neuropsychiatric Science and Systems Biological Medicine, Shanghai Jiao Tong University, Shanghai 200030, People's Republic of China. 'Department of Neurology, School of Medicine, Renji Hospital, Shanghai Jiao Tong University, Shanghai 200127, People's Republic of China. ${ }^{8}$ Psychological Medicine Center, The First Affiliated Hospital of Xinjiang Medical University, Urumqi, People's Republic of China. ${ }^{9}$ Shanghai Changning Mental Health Center, Shanghai 200030, People's Republic of China. ${ }^{10}$ Department of Psychiatry, First Teaching Hospital of Xinjiang Medical University, Urumqi, Xinjiang 830054, People's Republic of China.

Received: 7 January 2019 Accepted: 15 August 2019 Published online: 18 September 2019

\section{References}

1. Karam CS, Ballon JS, Bivens NM, Freyberg Z, Girgis RR, Lizardi-Ortiz JE, Markx S, Lieberman JA, Javitch JA. Signaling pathways in schizophrenia: emerging targets and therapeutic strategies. Trends Pharmacol Sci. 2010;31(8):381-90.

2. Burmeister M, McInnis MG, Zollner S. Psychiatric genetics: progress amid controversy. Nat Rev Genet. 2008;9(7):527-40.

3. Lieberman JA, Stroup TS, McEvoy JP, Swartz MS, Rosenheck RA, Perkins DO, Keefe RS, Davis SM, Davis CE, Lebowitz BD, et al. Effectiveness of antipsychotic drugs in patients with chronic schizophrenia. N Engl J Med. 2005:353(12):1209-23.

4. McCarthy S, Makarov V, Kirov G, Addington A, McClellan J, Yoon S, Perkins D, Dickel DE, Kusenda M, Krastoshevsky O, et al. Microduplications of 16p11. 2 are associated with schizophrenia. Nat Genet. 2009;41(11):1223-7.

5. O'Donovan MC, Craddock N, Norton N, Williams H, Peirce T, Moskvina V, Nikolov I, Hamshere M, Carroll L, Georgieva L, et al. Identification of loci associated with schizophrenia by genome-wide association and follow-up. Nat Genet. 2008;40(9):1053-5.

6. Purcell SM, Wray NR, Stone JL, Visscher PM, O'Donovan MC, Sullivan PF, Sklar P. Common polygenic variation contributes to risk of schizophrenia and bipolar disorder. Nature. 2009;460(7256):748-52.

7. Shi J, Levinson DF, Duan J, Sanders AR, Zheng Y, Pe'er I, Dudbridge F, Holmans PA, Whittemore AS, Mowry BJ, et al. Common variants on chromosome 6p22.1 are associated with schizophrenia. Nature. 2009; 460(7256):753-7.

8. Stefansson H, Ophoff RA, Steinberg S, Andreassen OA, Cichon S, Rujescu D, Werge T, Pietiläinen OPH, Mors O, Mortensen PB, et al. Common variants conferring risk of schizophrenia. Nature. 2009;460(7256):744-7.

9. Vacic V, McCarthy S, Malhotra D, Murray F, Chou H-H, Peoples A, Makarov V, Yoon S, Bhandari A, Corominas R, et al. Duplications of the neuropeptide receptor VIPR2 confer significant risk for schizophrenia. Nature. 2011; 471(7339):499-503.

10. Shi Y, Li Z, Xu Q, Wang T, Li T, Shen J, Zhang F, Chen J, Zhou G, Ji W, et al. Common variants on $8 \mathrm{p} 12$ and $1 \mathrm{q} 24.2$ confer risk of schizophrenia. Nat Genet. 2011:43(12):1224-7.

11. Li Z, Chen J, Yu H, He L, Xu Y, Zhang D, Yi Q, Li C, Li X, Shen J, et al. Genome-wide association analysis identifies 30 new susceptibility loci for schizophrenia. Nat Genet. 2017:49:1576.
12. Yao Y-G, Kong Q-P, Wang C-Y, Zhu C-L, Zhang Y-P. Different matrilineal contributions to genetic structure of ethnic groups in the silk road region in China. Mol Biol Evol. 2004;21(12):2265-80.

13. Luo M, Zhou X, Ji H, Ma W, Liu G, Dai D, Li J, Chang L, Xu L, Jiang L, et al. Population difference in the associations of KLOTH promoter methylation with mild cognitive impairment in Xinjiang Uygur and Han populations. PLoS One. 2015;10(7):e0132156.

14. Zhao TM, Lee TD. Gm and km allotypes in 74 Chinese populations: a hypothesis of the origin of the Chinese nation. Hum Genet. 1989;83(2):101-10.

15. Waisberg M, Joseph $\mathrm{P}$, Hale B, Beyersmann D. Molecular and cellular mechanisms of cadmium carcinogenesis. Toxicology. 2003;192(2-3):95-117.

16. Zalups RK, Ahmad S. Molecular handling of cadmium in transporting epithelia. Toxicol Appl Pharmacol. 2003;186(3):163-88.

17. Carrera N, Arrojo M, Sanjuán J, Ramos-Ríos R, Paz E, Suárez-Rama JJ, Páramo M, Agra S, Brenlla J, Martínez S, et al. Association study of nonsynonymous single nucleotide polymorphisms in schizophrenia. Biol Psychiatry. 2012;71(2):169-77.

18. Auton A, Brooks LD, Durbin RM, Garrison EP, Kang HM, Korbel JO, Marchini JL, McCarthy S, McVean GA, Abecasis GR. A global reference for human genetic variation. Nature. 2015;526(7571):68-74.

19. Schizophrenia Working Group of the Psychiatric Genomics C, Ripke S, Neale BM, Corvin A, JTR W, Farh K-H, Holmans PA, Lee P, Bulik-Sullivan B, Collier DA, et al. biological insights from 108 schizophrenia-associated genetic loci. Nature. 2014;511(7510):421-7.

20. Ehret GB, Munroe PB, Rice KM, Bochud M, Johnson AD, Chasman DI, Smith $A V$, Tobin MD, Verwoert GC, Hwang SJ, et al. Genetic variants in novel pathways influence blood pressure and cardiovascular disease risk. Nature. 2011;478(7367):103-9.

21. Wain LV, Verwoert GC, O'Reilly PF, Shi G, Johnson T, Johnson AD, Bochud M, Rice KM, Henneman P, Smith AV, et al. Genome-wide association study identifies six new loci influencing pulse pressure and mean arterial pressure. Nat Genet. 2011:43(10):1005-11.

22. Locke AE, Kahali B, Berndt SI, Justice AE, Pers TH, Day FR, Powell C, Vedantam S, Buchkovich ML, Yang J, et al. Genetic studies of body mass index yield new insights for obesity biology. Nature. 2015; 518(7538):197-206.

23. Li D, Achkar JP, Haritunians T, Jacobs JP, Hui KY, D'Amato M, Brand S, Radford-Smith G, Halfvarson J, Niess JH, et al. A pleiotropic missense variant in SLC39A8 is associated with Crohn's disease and human gut microbiome composition. Gastroenterology. 2016;151(4):724-32.

24. $\mathrm{Ng}$ E, Lind PM, Lindgren C, Ingelsson E, Mahajan A, Morris A, Lind L. Genome-wide association study of toxic metals and trace elements reveals novel associations. Hum Mol Genet. 2015;24(16):4739-45.

25. Willer CJ, Schmidt EM, Sengupta S, Peloso GM, Gustafsson S, Kanoni S, Ganna A, Chen J, Buchkovich ML, Mora S, et al. Discovery and refinement of loci associated with lipid levels. Nat Genet. 2013;45(11):1274-83.

26. First MB, Spitzer RL, Gibbon M, JB W. Structured Clinical Interview for DSMIV-TR Axis I Disorders, Research Version, Patient Edition. (SCID-I/P). Biometrics Research. New York: State Psychiatric Institute; 2002.

27. Li Z, Zhang Z, He Z, Tang W, Li T, Zeng Z, He L, Shi Y. A partition-ligationcombination-subdivision EM algorithm for haplotype inference with multiallelic markers: update of the SHEsis (http://analysis.bio-x.cn. Cell Res. 2009;19(4):519-23.

28. Shen J, Li Z, Chen J, Song Z, Zhou Z, Shi Y. SHEsisPlus, a toolset for genetic studies on polyploid species. Sci Rep. 2016;6:24095.

29. Faul F, Erdfelder E, Lang AG, Buchner A. G* power 3: a flexible statistical power analysis program for the social, behavioral, and biomedical sciences. Behav Res Methods. 2007;39(2):175-91.

30. Higgins JPT, Thompson SG, Deeks JJ, Altman DG. Measuring inconsistency in meta-analyses. BMJ. 2003;327(7414):557-60.

31. Price AL, Helgason A, Palsson S, Stefansson H, St Clair D, Andreassen $\mathrm{OA}$, Reich D, Kong A, Stefansson K. The impact of divergence time on the nature of population structure: an example from Iceland. PLoS Genet. 2009;5(6):e1000505.

32. Engelken J, Espadas G, Mancuso FM, Bonet N, Scherr AL, Jimenez-Alvarez V, Codina-Sola M, Medina-Stacey D, Spataro N, Stoneking M, et al. Signatures of evolutionary adaptation in quantitative trait loci influencing trace element homeostasis in liver. Mol Biol Evol. 2016;33(3):738-54.

33. Zhang C, Li J, Tian L, Lu D, Yuan K, Yuan Y, Xu S. Differential natural selection of human zinc transporter genes between African and non-African populations. Sci Rep. 2015;5:9658. 
34. Li M, Wu D-D, Yao Y-G, Huo Y-X, Liu J-W, Su B, Chasman DI, Chu AY, Huang $T$, Qi $L$, et al. Recent positive selection drives the expansion of a schizophrenia risk nonsynonymous variant at SLC39A8 in Europeans. Schizophr Bull. 2016:42(1):178-90.

35. Aschner M, Guilarte TR, Schneider JS, Zheng W. Manganese: recent advances in understanding its transport and neurotoxicity. Toxicol Appl Pharmacol. 2007;221(2):131-47.

36. Crichton RR, Dexter DT, Ward RJ. Brain iron metabolism and its perturbation in neurological diseases. J Neural Transm (Vienna, 1996). 2011;118(3):301-14.

37. Wright RO, Baccarelli A. Metals and neurotoxicology. J Nutr. 2007; 137(12):2809-13.

38. Bitanihirwe BK, Cunningham MG: Zinc: the brain's dark horse. Synapse. 2009; 63(11):1029-1049.

39. Nakashima AS, Dyck RH. Zinc and cortical plasticity. Brain Res Rev. 2009; 59(2):347-73.

40. Dalton TP, He L, Wang B, Miller ML, Jin L, Stringer KF, Chang X, Baxter CS, Nebert DW. Identification of mouse SLC39A8 as the transporter responsible for cadmium-induced toxicity in the testis. Proc Natl Acad Sci U S A. 2005; 102(9):3401-6.

41. Marchetti C. Interaction of metal ions with neurotransmitter receptors and potential role in neurodiseases. Biometals : an international journal on the role of metal ions in biology, biochemistry, and medicine. 2014;27(6):1097-113.

42. Zhang R, Witkowska K, Afonso Guerra-Assuncao J, Ren M, Ng FL, Mauro C, Tucker AT, Caulfield MJ, Ye S. A blood pressure-associated variant of the SLC39A8 gene influences cellular cadmium accumulation and toxicity. Hum Mol Genet. 2016;25(18):4117-26.

43. Rentschler G, Kippler M, Axmon A, Raqib R, Skerfving S, Vahter M, Broberg K. Cadmium concentrations in human blood and urine are associated with polymorphisms in zinc transporter genes. Metallomics : integrated biometal science. 2014;6(4):885-91.

44. Wu Y, Yao Y-G, Luo X-J. SZDB: a database for schizophrenia genetic research. Schizophr Bull. 2016;43(2):459-71.

45. Costas J. The highly pleiotropic gene SLC39A8 as an opportunity to gain insight into the molecular pathogenesis of schizophrenia. American journal of medical genetics Part B, Neuropsychiatric genetics. 2018;177(2):274-83.

46. Hess JL, Tylee DS, Barve R, de Jong S, Ophoff RA, Kumarasinghe N, Tooney P, Schall U, Gardiner E, Beveridge NJ, et al. Transcriptome-wide mega-analyses reveal joint dysregulation of immunologic genes and transcription regulators in brain and blood in schizophrenia. Schizophr Res. 2016;176(2-3):114-24.

47. Wockner LF, Noble EP, Lawford BR, Young RM, Morris CP, Whitehall VL, Voisey J. Genome-wide DNA methylation analysis of human brain tissue from schizophrenia patients. Transl Psychiatry. 2014;4:e339.

48. Baum AE, Hamshere M, Green E, Cichon S, Rietschel M, Noethen MM, Craddock N, McMahon FJ. Meta-analysis of two genome-wide association studies of bipolar disorder reveals important points of agreement. Mol Psychiatry. 2008;13(5):466-7.

49. Ollila HM, Soronen P, Silander K, Palo OM, Kieseppa T, Kaunisto MA, Lonnqvist J, Peltonen L, Partonen T, Paunio T. Findings from bipolar disorder genome-wide association studies replicate in a Finnish bipolar family-cohort. Mol Psychiatry. 2009;14(4):351-3.

50. Muglia P, Tozzi F, Galwey NW, Francks C, Upmanyu R, Kong XQ, Antoniades A, Domenici E, Perry J, Rothen S, et al. Genome-wide association study of recurrent major depressive disorder in two European case-control cohorts. Mol Psychiatry. 2010;15(6):589-601.

\section{Publisher's Note}

Springer Nature remains neutral with regard to jurisdictional claims in published maps and institutional affiliations.

\section{Ready to submit your research? Choose BMC and benefit from:}

- fast, convenient online submission

- thorough peer review by experienced researchers in your field

- rapid publication on acceptance

- support for research data, including large and complex data types

- gold Open Access which fosters wider collaboration and increased citations

- maximum visibility for your research: over $100 \mathrm{M}$ website views per year

At BMC, research is always in progress.

Learn more biomedcentral.com/submissions 